\section{STATUS OF THE SYNCHROTRON RADIATION MONITORS FOR THE APS FACILITY RINGS*}

\author{
A. Lumpkin and B. Yang
}

Argonne National Laboratory, 9700 S. Cass Ave., Argonne, II 60439 USA

\section{Abstract}

Initial results from the optical synchrotron radiation (OSR) monitors for the Advanced Photon Source (APS) have been obtained. Data using electron beams on the positron accumulator ring (PAR) at $400 \mathrm{MeV}$, the injector synchrotron (IS) up to 7-GeV, and the main storage ring (SR) at 4.5 and $7 \mathrm{GeV}$ address both transverse profiles and/or longitudinal bunch length. Recent measurements on OSR transported outside of the PAR and IS enclosures include transverse damping information. Streak camera and photodiode detectors have been used to measure bunch length compression $\sigma_{\mathrm{l}}=1000$ to $400 \mathrm{ps}$ on the PAR and damping on the IS of $\sigma_{\mathrm{t}}=200$ to $75 \mathrm{ps}$. First transverse images have been recorded on the main ring from a single turn and for stored beam.

\section{INTRODUCTION}

The Advanced Photon Source (APS) [1] includes a 450$\mathrm{MeV}$ positron accumulator ring (PAR), an injector synchrotron (IS) that ramps the beam energy to $7 \mathrm{GeV}$, and the $7-\mathrm{GeV}$ main storage ring (SR). Characterizations of the beams circulating in these machines have begun using optical synchrotron radiation (OSR) [2]. Images of transverse beam size in all three rings, multiturn data using photomultiplier tubes and photodiodes, and bunch length data using both photodiode and dualsweep streak camera techniques have been used to support commissioning. The latter are the first of their kind on a circular accelerator in the USA.

In the PAR, estimates of transverse emittance and the tracking of effects of the 12th harmonic cavity on bunch compression have resulted. In the IS both the transverse damping and aspects of longitudinal damping during the ramping cycle have been monitored. For the SR, an initial in-tunnel installation on a bending magnet beam port of a Questar telemicroscope and a charge-coupled device (CCD) camera have allowed the imaging via OSR of the beam on a single-turn and first stored beam. The plans for both OSR and $x$-ray synchrotron radiation (XSR) monitoring of the beam are outlined. Eventually, both bending a magnet and a "diagnostics undulator" will be used as sources of XSR for beam characterization [3].

\section{EXPERIMENTAL BACKGROUND}

The parameter spaces of the three rings are sufficiently different to require adjustments to detectors and lenses for each case. The general features are shown in Table 1. The PAR revolution time is the shortest at $102.3 \mathrm{~ns}$ with the IS and SR at

*Work supported by the U.S. Department of Energy, Office of Basic Energy Sciences, under Contract No. W-31-109-ENG-38.
1.23 and $3.68 \mu \mathrm{s}$, respectively. For the longer bunch lengths of the PAR, which even after damping would be about $\sigma=300 \mathrm{ps,}$ a fast photodiode has been used. At this point a dual-sweep streak camera has been used for both PAR and the IS bunch length dynamics, and it is planned for the SR. The transverse profiles have been obtained via OSR imaging with the camera/ lens system focused on the bending magnet source point.

Table 1: APS Parameters for Beam Diagnostics

\begin{tabular}{|c|c|c|c|}
\hline & PAR & IS & SR \\
\hline RF Frequency & $\begin{array}{l}9.77 \text { or } \\
117 \mathrm{MHz}\end{array}$ & $351.93 \mathrm{MHz}$ & $351.93 \mathrm{MHz}$ \\
\hline Revolution Time & $102.3 \mathrm{~ns}$ & $1.228 \mu \mathrm{s}$ & $3.68 \mu \mathrm{s}$ \\
\hline No. of Bunches & 1 & 1 & 1 to 60 \\
\hline Min. Bunch Spacing & - & $\cdots$ & $20 \mathrm{~ns}$ \\
\hline Bunch Length $(2 \sigma)$ & 30 to $0.6 \mathrm{~ns}$ & 122 ps & $35-100 \mathrm{ps}$ \\
\hline Min. Avg Bearn Current & $\begin{array}{l}1.4 \mathrm{~mA} \\
\text { I linac pulse } \\
\text { injected }\end{array}$ & - & $\begin{array}{l}0.22 \mathrm{~mA} \\
\text { for single } \\
\text { bunch }\end{array}$ \\
\hline Max. Avg Beam Current & $\begin{array}{l}33.4 \mathrm{~mA} \\
24 \text { linac } \\
\text { pulses injected }\end{array}$ & $4.7 \mathrm{~mA}$ & $\begin{array}{l}5 \mathrm{~mA} \\
\text { for single } \\
\text { bunch }\end{array}$ \\
\hline $\begin{array}{l}\text { Max. Intensity } \\
\text { particles/sec }\end{array}$ & $3.6 \times 10^{10}$ & $3.6 \times 10^{10}$ & $\begin{array}{l}2.2 \times 10^{10} \\
\text { Sunch/mA }\end{array}$ \\
\hline
\end{tabular}

\section{A. Transverse Beam Size}

In our initial mode, an in-tunnel installation of a leadshielded CCD camera with remotely controlled zoom lens (16$160 \mathrm{~mm}$ focal length) was used. In the PAR, exit ports from two dipole vacuum chambers were utilized, one source point at high energy dispersion and one at low dispersion. More recently, the OSR beams have been transported out of the accelerator enclosure (see Fig. 1), and this has facilitated the use of a fast photodiode, a streak camera, and soon a gated, intensified camera. On this table a CCD camera with a 500$\mathrm{mm}$ focal length lens with a $\mathrm{X} 2$ magnifier provides a limiting resolution, $\sigma_{\mathrm{res}}-200 \mu \mathrm{m}$. A $450 \times 10 \mathrm{~nm}$ band pass filter and a neutral density (ND) filter of ND 2.0 to 3.0 are routinely used.

For the IS, a Questar telemicroscope (model FR1) is located on an optics table in a lab above the IS accelerator tunnel. A series of mirrors brings the OSR to the lens. Four focal lengths ranging from $220 \mathrm{~mm}$ to $3100 \mathrm{~mm}$, an ND filter wheel with selection from 0.0 to $2.5 \mathrm{ND}$, and a $488 \times 1 \mathrm{~nm}$ band pass filter are used to adjust the beam spectrum and intensity. At the fully magnified position, the limiting resolution is about $\sigma_{\text {res }}=60 \mu \mathrm{m}$ based on tests with an illuminated circular aperture of 12- $\mu \mathrm{m}$ diameter. A UV-capable Questar has been installed
The submitted manuscript has been authored by a contractor of the U.S. Government under contract No. W-31-109ENG-38. Accordingly, the U.S. Government retains a nonexclusive, royalty-free license so publish or reproduce the published form of this contribution, or allow others to do so, for U. S. Government purposes. 


\section{DISCLAIMER}

This report was prepared as an account of work sponsored by an agency of the United States Government. Neither the United States Government nor any agency thereof, nor any of their employees, makes any warranty, express or implied, or assumes any legal liability or responsi'bility for the accuracy, completeness, or usefulness of any information, apparatus, product, or process disclosed; or represents that its use would not infringe privately owned rights. Reference herein to any specific commercial product, process, or service by trade name, trademark, manufacturer, or otherwise does not necessarily constitute or imply its endorsement, recommendation, or favoring by the United States Government or any agency thereof. The views and opinions of authors expressed herein do not nocessarily state or reflect those of the United States Government or any agency thereof: 


\section{DISCLAIMER}

Portions of this document may be illegible in electronic image products. Images are produced from the best available original document. 


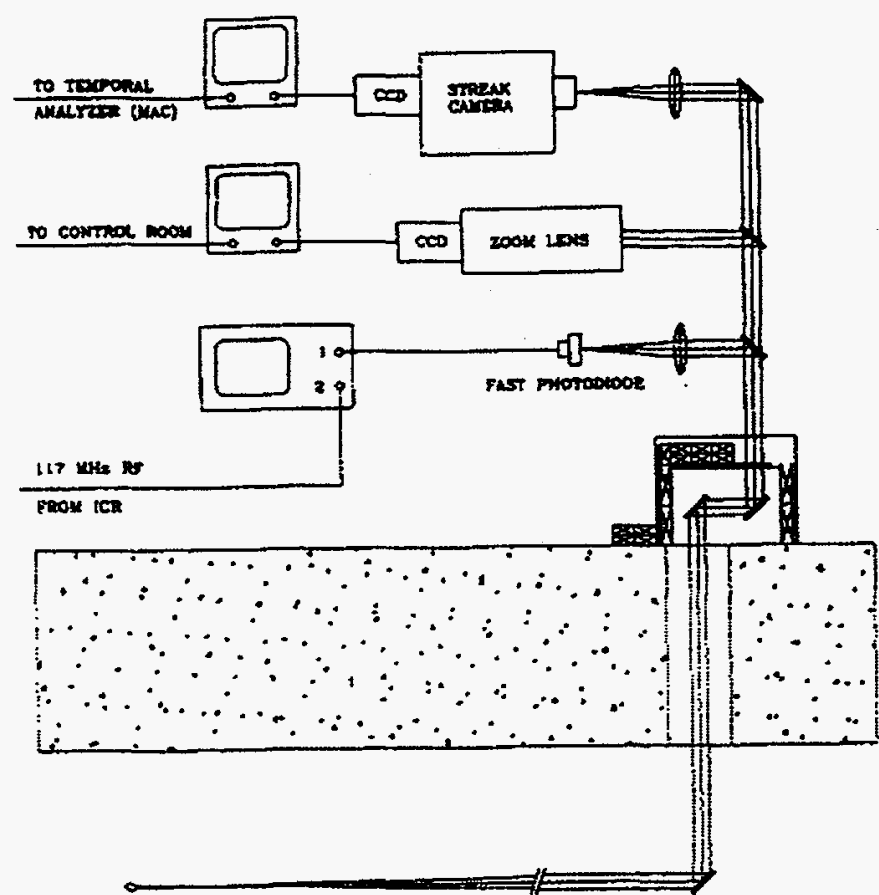

Figure 1: Schematic of OSR transport by mirrors out of the PAR and IS tunnels to detectors on an optics table.

in the SR tunnel on a bending magnet OSR port. The initial invacuum moly mirror is water-cooled but may only be used at low stored beam currents in early commissioning. A slotted Glidcop mirror, which will allow the high power, low-divergence angle $x$-rays to pass through the on-axis slot, will be used in later commissioning.

\section{B. Bunch Length Measurements}

In the PAR, the original 30-ns-long linac macropulse is damped to about $\sigma=1 \mathrm{~ns}$ in tens of $\mathrm{ms}$ at $E=400 \mathrm{MeV}$ and the fundamental $9.77-\mathrm{MHz}$ if cavity at nominal power. Additional compression by a factor of three is obtained by turning on the 12th harmonic cavity (at $117.3 \mathrm{MHz}$ ). An Antel photodiode (model AR-S1) with $<100$ ps rise time, an rf amplifier (10.1$4.2 \mathrm{GHz}$ ), and either a Tektronix 11802 digital sampling oscilloscope with a $50 \mathrm{GSa} / \mathrm{s}$ sampling head or an HP model $54542 \mathrm{~A} 500-\mathrm{MHz}$ BW digitizing oscilloscope were used to record the photodiode signals. The system resolution was observed to be about $\sigma=300-350$ ps.

Additionally, a Hamamatsu C5680 dual-sweep streak system has been used to provide complementary bunch length information on the PAR as well as on the injector synchrotron. Both if synchronized or synchroscan and multiple single trigger techniques have been used. These data in the next section are the first measurements using such a technique on a circular accelerator in the USA.

\section{RESULTS AND SR PLANS}

\section{A. Transverse}

For transverse beam size, the results for the three rings are summarized as follows. For the PAR, a damped beam image profile (see Fig. 2) was measured to have a $\Delta x=3.6 \mathrm{~mm}$ (FWHM). Assuming a Gaussian profile and a camera gamma factor of 0.66 , this implies a $\sigma_{x} \sim 1.2 \mathrm{~mm}$ observed. This would include the contributions of betatron motion $\left(\beta_{x}=2.9 \mathrm{~m}\right)$ and dispersion in this case. This would imply a horizontal emittance $\sigma_{\varepsilon x}-0.22 \mathrm{~mm}$ mrad as compared to the scaled, theoretical emittance of $0.29 \mathrm{~mm}$ mrad at $400 \mathrm{MeV}$.

$x$ Profile

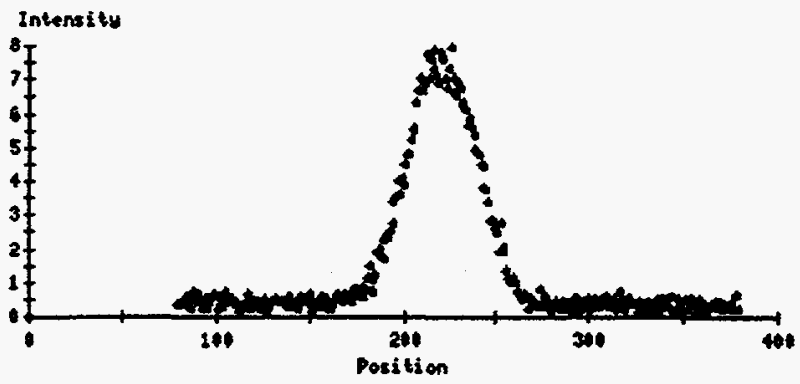

Figure 2: Video image profile of the PAR beam after damping using OSR. The total observed size was $\Delta x=3.6 \mathrm{~mm}$ (FWHM) and $\Delta y \cong 0.6 \mathrm{~mm}$ (FWHM).

For the IS, the reduction of the transverse profile FWHM was observed by capturing a series of digital video image sequences in 33-ms steps. Measurements of the extracted beam emittance in the transport line between the IS and SR have not yet been done.

For the storage ring, we recorded the first OSR image from a bending magnet on March 18, 1995. It is shown in Fig. 3. This was obtained on a single turn at $7-\mathrm{GeV}$ with about $1 \mathrm{nC}$ in the bunch. The first OSR image of a stored beam is shown in Fig. 2 of [4].

\section{B. Longitudinal}

Bunch length measurements on the PAR have tracked the stacking, damping, and compression cycle. As shown in Fig. 4 , an overlapping of bunch profiles for the photodiode, from early to late in the cycle, are displayed. A phase shift (towards the left) has also been detected. The most intense, negative going signal on the left of the profiles corresponds to a total measured $\sigma_{\mathrm{t}} \sim 600 \mathrm{ps}$. The 12 th harmonic was not optimized, and the system resolution with the HP digitizing oscilloscope is still convolved. Subsequent streak camera data on a single, damped bunch have shown bunches with $\sigma=400$ ps.

On the IS, the bunch length was tracked during the 230ms-long energy ramping cycle ( $400 \mathrm{MeV}$ to $7 \mathrm{GeV}$ ) using the dual sweep features of the streak camera. The vertical time axis covered $\sim 1500$ ps and the horizontal axis covered $\sim 100$ ms. A DG535 delay generator was used to position the acquisition in the cycle. Figure 5 shows an example in the 35-to130 -ms portion of the cycle. The bunch compression from about 400 ps (FWHM) at the left to 178 ps (FWHM) on the right is obvious. By using a narrower region of interest ( 1 -ms wide), a FWHM of $158 \mathrm{ps}\left(\sigma_{\mathrm{t}}=67 \mathrm{ps}\right)$ is obtained. The wider window integrates over a detectable phase shift which appears to be a part of a relative phase oscillation at $120-\mathrm{Hz}$ frequency. 

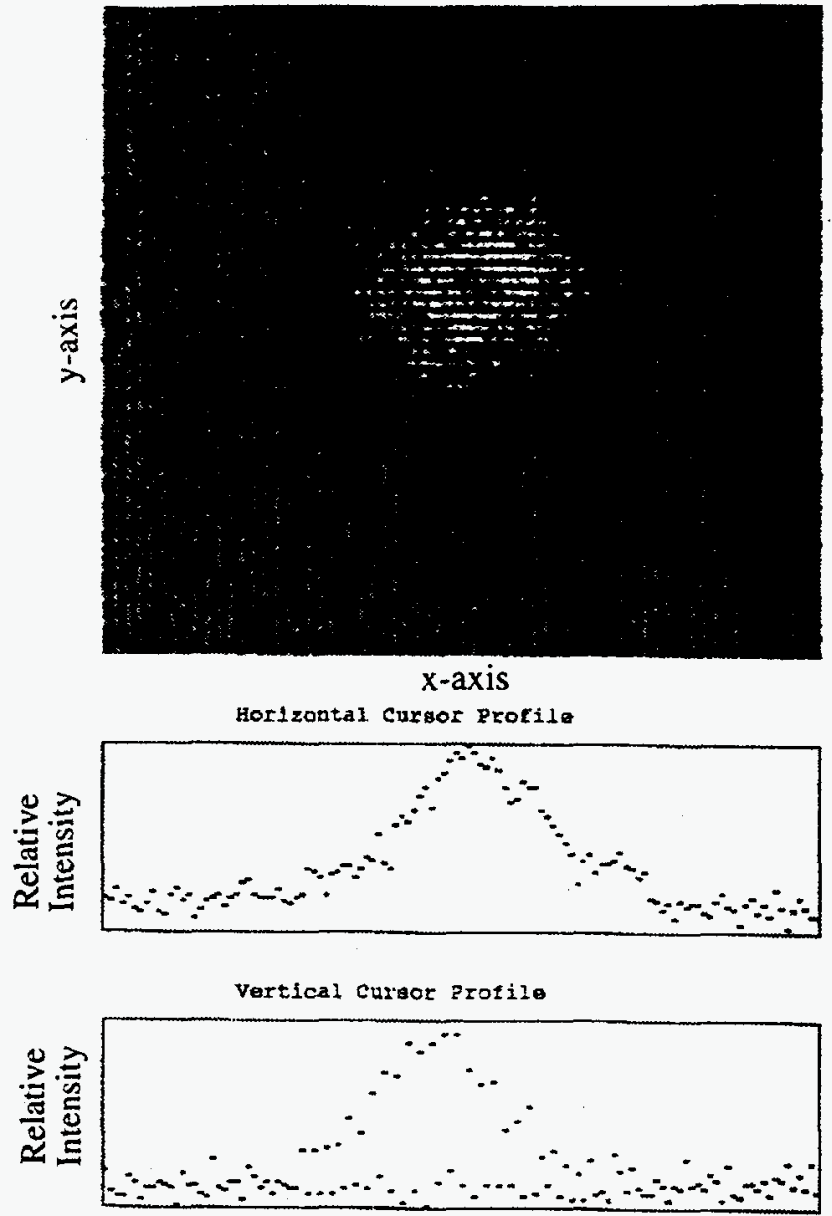

Figure 3: First synchrotron radiation image of the 7-GeV electron beam in the APS main storage ring. These data are from only a single pass.

Further studies addressing single turn, single bunch performance are planned as well as addressing the source of the-120 $\mathrm{Hz}$ effect.
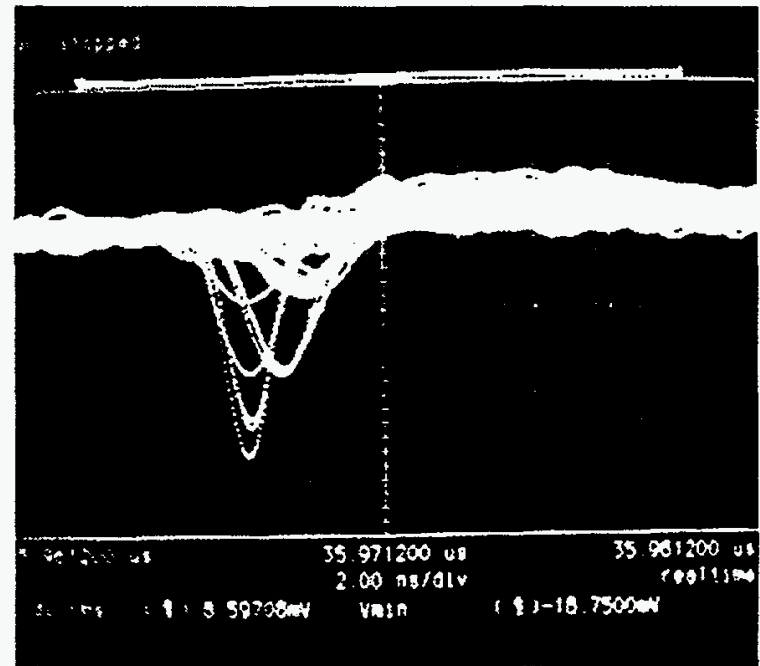

Figure 4: Photodiode data showing the PAR bunch length dynamics during the compression cycle. The final total observed bunch length was about $\sigma=600$ ps in this case. The horizontal scale is 2 ns/division.

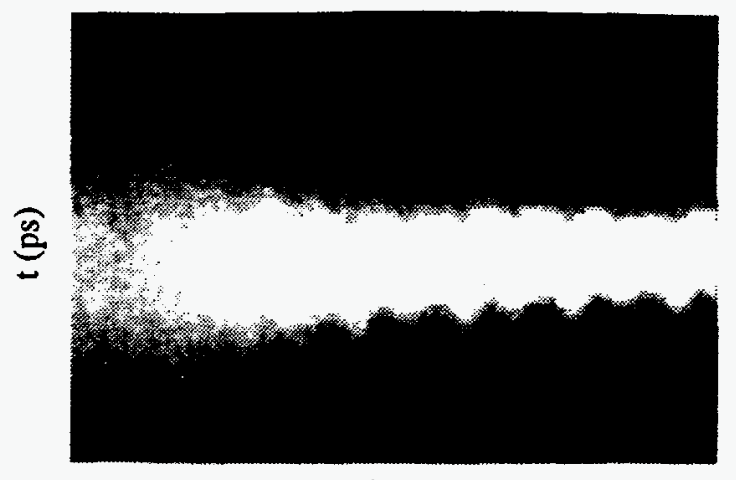

$\mathrm{T}(\mathrm{ms}) \rightarrow$

Figure 5: Dual-sweep streak image of the IS bunch length variation during the energy ramping cycle. These data cover from 35 to 130

$\mathrm{ms}$ in the ramp cycle on the horizontal axis and $1500 \mathrm{ps}$ on the vertical axis. The bunch length is about 158 ps (FWHM) at the righthand side.

\section{Long-term Plans}

Our long-term plans for the storage ring beam characterization include the extension of beam imaging to $x$-ray synchrotron radiation (XSR) and the use of both the bending magnet source and a diagnostics undulator. The issue of actual beam divergence for various vertical coupling ratios versus the radiation cone divergence is discussed in [3]. We have selected a $1.8-\mathrm{cm}$ period device with a $2.5-$ to $3.0-\mathrm{m}$ length and a 2- to 3- $\mu$ rad cone angle as a primary means of obtaining sensitivity to the baseline $8-\mu \mathrm{rad}$ particle beam divergence.

\section{SUMMARY}

In summary, we have obtained OSR images of the circulating particle beam (electrons so far) in the three rings at APS. Transverse size, emittance, and bunch length measurements have been obtained and comparison to design objectives has begun. Characterization of the low-emittance SR beams using both OSR and XSR will be a primary objective in the next year.

\section{REFERENCES}

[1] D.E. Moncton, E. Crosbie, and G.K. Shenoy "Overview of the Advanced Photon Source," Rev. Sci. Instruments, 60 (7), July 1989.

[2] A.H. Lumpkin, W. Sellyey, and B. Yang, "Proposed Time-resolved Photon/Imaging Diagnostics for the APS," Proc. of the 1994 European Particle Accelerator Conference, London, England, Vol. 2, pp. 1687 (1994).

[3] B. Yang and A.H. Lumpkin, "The Planned Photon Diagnostics Beamlines at the APS," Proc. of the 1994 Beam Instrumentation Workshop, Vancouver, B.C., Oct. 2-6, 1994.

[4] A.H. Lumpkin, et al., "Initial Diagnostics Commissioning Results for the Advanced Photon Source (APS)," these proceedings.

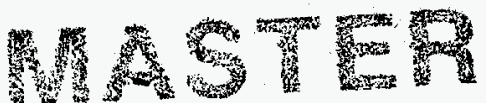

